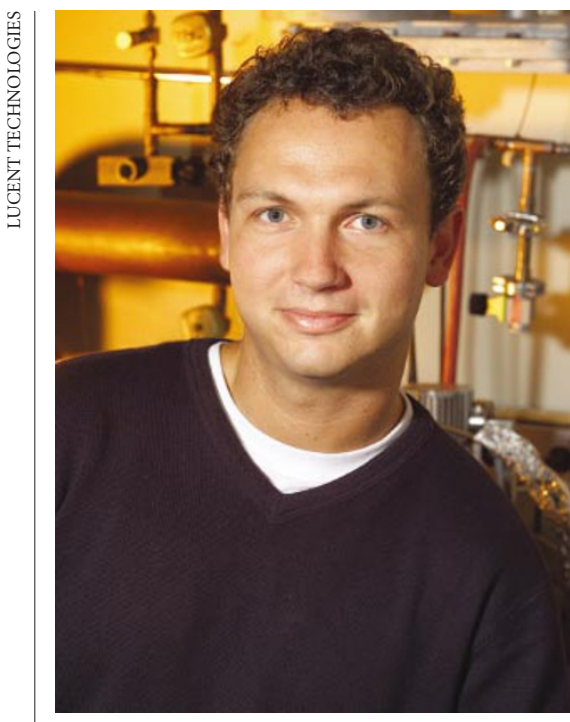

Rising star: Jan Hendrik Schön's impressive results have secured him several awards.

allegations, Schön says that he is cooperating fully with the review committee. "I'm collaborating with my colleagues to reproduce these results and show them to the committee," he says. "I am trying to focus on the science."

At 31 years old, Schön is seen as one of the most able young physicists in nanotechnology. In the six years since he got his $\mathrm{PhD}$ at the University of Konstanz in Germany, he has produced over 100 papers and claimed several patents, as well as winning awards for his work in both the United States and Germany.

The speed and scope of his findings have aroused admiration among researchers - but some of his results have proved hard to reproduce. Robert Dynes at the University of California, San Diego, for example, has tried to replicate some of Schön's results for molecular switches that are turned on and off when an electric field is applied.

"I was fascinated by the results and frustrated that I couldn't reproduce them, and I didn't totally understand why I couldn't," recalls Dynes. The problem, he says, was that the applied electric field kept destroying critical components of the experiment.

Dynes is not alone. Groups at the French Atomic Energy Commission, Harvard University, Princeton and elsewhere say that they have so far been unable to reproduce some of Schön's results.

1. Schön, J. H., Meng, H. \& Bao, Z. Science 294,

2138-2140 (2001).

2. Schön, J. H., Meng, H. \& Bao, Z. Nature 413,

713-716 (2001)

3. Schön, J. H., Berg, S., Kloc, Ch. \& Batlogg, B. Science 287, 1022-1023 (2000).

4. Schön, J. H., Kloc, Ch., Haddon, R. C. \& Batlogg, B. Science 288, 656-658 (2000).

Schön, J. H., Dodabalapur, A., Kloc, Ch. \& Batlogg, B. Science 290, 963-965 (2000).

6. Schön, J. H., Kloc, Ch. \& Batlogg, B. Appl. Phys. Lett. 77, 3776-3778 (2000).

\title{
Public ponders biotech issues
}

Quirin Schiermeier, Munich

European citizens hold more finely differentiated and balanced views on genetically modified foods than scientists and politicians give them credit for, says a study carried out for the European Commission.

False interpretations of what the public wants are largely responsible for the difficulties faced by European policy-makers in managing agricultural biotechnology, the study claims.

The study, Public Perceptions of Agricultural Biotechnologies in Europe, is based on an analysis of discussions held between 1998 and 2000 by 55 focus groups in Germany, France, Britain, Italy and Spain, as well as interviews with activists, scientists and others who are more directly involved with the agricultural biotechnology industry. It was coordinated by Brian Wynne, a sociologist at Lancaster University, UK, who established his reputation by using such methods to assess the public's perception of nuclear power in the 1980s.

"Almost all popular opinions on the alleged misperceptions about the alleged view of the 'man and woman on the street' turned out to be simply myths," the study says. "Participants did not, overall, express entrenched opinions 'for' or 'against' genetically modified organisms."

The researchers found that public mistrust of regulatory bodies such as food-safety agencies was the underlying basis of suspicions of agricultural biotechnology.

Better information will not, in itself, restore the public's trust in these regulators, the study concludes. Instead, it says that "more profound changes in institutional culture and practice" will be required. It suggests imposing heavy sanctions on companies or research institutions if any harm is caused by new technologies.

But Derek Burke, a retired molecular biologist and former chairman of the UK Advisory Committee on Novel Food and Processes, is sceptical about the study's findings, saying that he is uneasy about both its tone and its content. Burke argues that focus groups can easily be led towards a desired conclusion.

"This is an interesting contribution from a group of people with strong views," says Burke. "But their arguments reflect no more than the current media coverage."

\section{www.pabe.net}

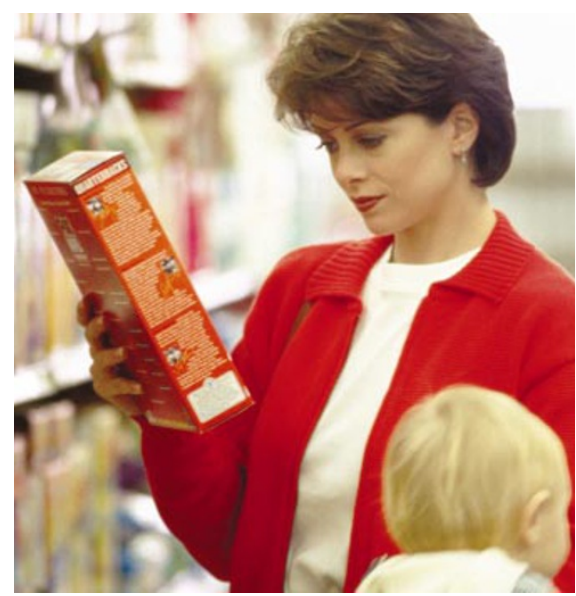

Food for thought: the public's perceived opinions on genetic modification are open to question.

\section{US 'overspent' on collider project}

\section{Geoff Brumfiel, Washington}

The US National Science Foundation (NSF) is under fire over its financial management of major research projects - including its contribution to the Large Hadron Collider, the particle collider being built at CERN, the European particle-physics laboratory in Geneva.

An audit by the research agency's inspector general, Christine Boesz, found that the NSF failed to track properly the full costs of the projects. For example, the agency told the National Science Board, its governing body, that its contribution to detectors at the Large Hadron Collider would cost $\$ 81$ million. But, the audit says, a further $\$ 57$ million will be needed for advanced computing and maintenance if US scientists are to glean any data from the detectors.

“The inspector general's report has confirmed my fears that there is little oversight of NSF's large facilities," says Senator Kit Bond (Republican, Missouri), the senior Republican on the Senate subcommittee that funds the NSF. At a hearing on 15 May, Bond nonetheless expressed his support for a plan that would see the NSF's budget double in size within five years (see Nature 417, 209; 2002).

NSF officials claim that the inspector general's report is misleading. Robert Eisenstein, who heads the NSF's Directorate of Mathematical and Physical Sciences, says that the $\$ 81$ million will be enough to complete the parts of the detectors that are specified by the NSF's agreement with CERN. "We will deliver exactly what we said we will deliver," he says. The proposed $\$ 57$ million will cover maintenance and computing technology that had not even been invented when the agreement was signed, says Eisenstein. 


\section{Chemists synthesize a single naming system}

\section{David Adam, London}

An international team of chemists is working on something that chemistry sorely lacks - a consistent and comprehensive way of labelling all chemical compounds.

The new technique will apply computer algorithms to molecular structures, generating a unique digital signature for any chemical compound. The new labels are not intended to replace common chemical names, but to allow easier linking to compounds in online chemical databases and journals.

"The hope is that all organizations that handle information on chemicals will be able to use a single format to say what the chemical is," says Alan McNaught, general manager of the production division at the Royal Society of Chemistry in Cambridge, who coordinates the project for the International Union of Pure and Applied Chemistry (IUPAC).

Right now there is no single international standard for identifying chemicals. The IUPAC and the American Chemical Society use different rules. Some drug companies, as well as different branches of chemistry, have their own chemical-naming systems. Even simple structures can cause confusion. For example, the formal name for acetic acid, the main ingredient in vinegar, is ethanoic acid.

IUPAC believes that its new system which would be freely available to all — could unify the different approaches. Tentatively

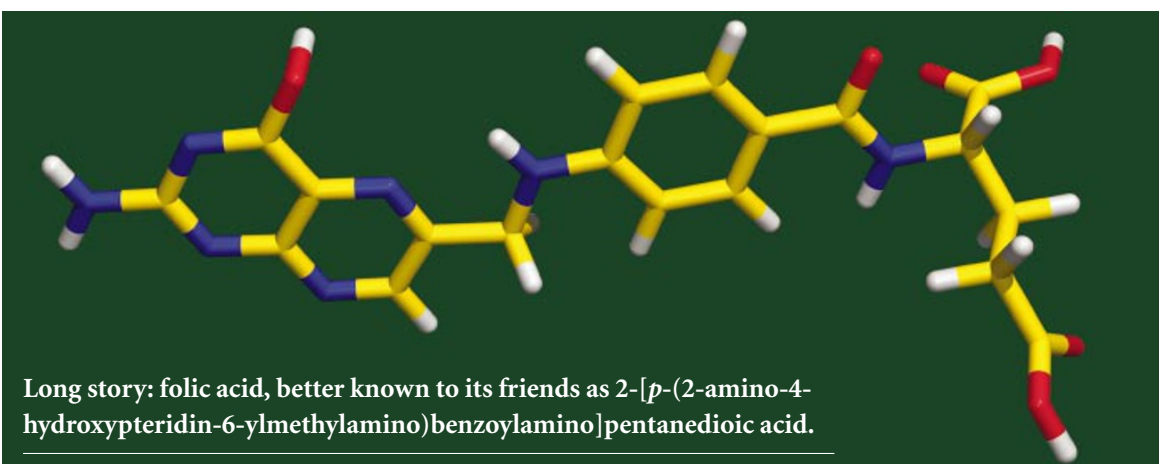

known as IChI, for IUPAC chemical identifier, its development is being led by a team at the US National Institute of Standards and Technology (NIST) in Gaithersburg, Maryland.

A preliminary version of the software covering well-defined, covalently bonded organic molecules was released this year to let other chemists test the idea. It labels each atom in a compound in a way that does not depend on how the structure is drawn, and converts the label to a string of characters. The format has not been finalized, but at present ethane is ' $\mathrm{C} 3 \mathrm{C} 3,2-1$ ', for example, and acetone is 'C3C3OC, 4-1-2-3' (the labels are easily converted to structures using the algorithm). The process is reversible, so molecular structures can be generated from the identifiers.

The next step is to extend the system to include more complex organic compounds, such as polymers, and ultimately to tackle inorganic compounds. By adding it to software packages commonly used to draw chemical structures, the NIST team hopes that IChI will enter into widespread use.

In effect, the IChI number will provide each chemical molecule with a digital object identifier (DOI) - a concept increasingly being applied to everything from scientific papers to individual genes. Jonathan Goodman, a chemist at the University of Cambridge, says chemistry suits this approach well. "Molecules are a wonderful unit of information to treat in this way," he says. "They are complex enough to have lots of interesting features and difficulties but simple enough to represent quite a small subset." www.iupac.org/projects/2000/ 2000-025-1-800.html

\section{NASA's critics demand a few more steps into space}

Tony Reichhardt, Washington

Critics of Sean O'Keefe, the new NASA administrator, are complaining that his nuts-and-bolts management style is leaving the space agency bereft of what ex-president George Bush once called "the vision thing".

The agency's human spaceflight programme is "adrift, with no clear vision or commitment to any goals after the completion of the International Space Station", Congressman Nick Lampson (Democrat, Texas) told the House of Representatives on 15 May.

Lampson was introducing the Space Exploration Act of 2002, which would require NASA to complete a series of specific tasks, starting with building a reusable space vehicle within eight years that is capable of carrying astronauts beyond Earth orbit to locations where large space telescopes could be constructed. Under the act, NASA would also be charged with building, within 10 years, a vehicle capable of reaching nearEarth asteroids. A lunar research facility would follow within 15 years, and a spacecraft for reaching Mars within 20.

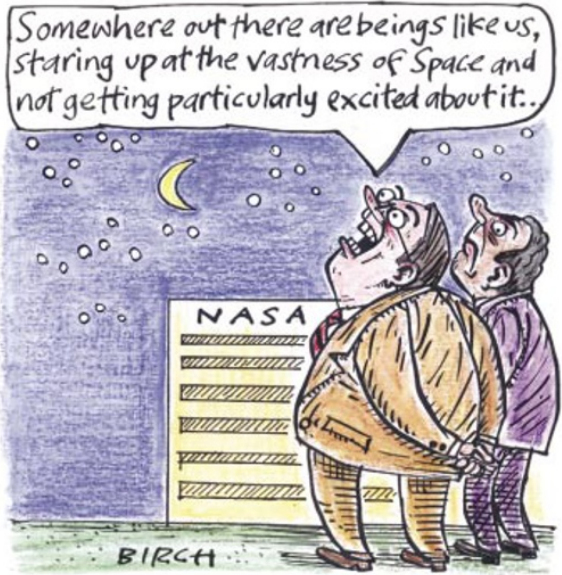

The bill takes an approach that is becoming fashionable among long-term space planners: it proposes a series of incremental steps, rather than the grand sweep of a single mission to Mars. It calls for a competitive programme, run by a new Office of Exploration, modelled on NASA's Discovery series of planetary-exploration missions, with an initial budget of $\$ 50$ million next year and \$200 million in 2004

Lampson's proposal contrasts sharply with the approach being taken by the White House and O'Keefe, who has made it clear that he envisages a period of incremental technology development for NASA, rather than identifying any grandiose new goals.

Although Lampson's bill has little chance of passing Congress, NASA's recent 'go-slow' strategy has been criticized by other politicians, including Tom DeLay (Republican, Texas), the majority whip in the House and one of Washington's most powerful figures. During a congressional hearing last month, DeLay branded O'Keefe's plans for human spaceflight "timid and anaemic".

Most of the bill's sponsors are from districts near NASA's Johnson Space Center in Texas, where the US astronaut programme is based. But its arrival, observers say, reflects a growing weight of opinion that, with the space station downsized and no other large projects on the horizon, NASA's 40-year-old human-spaceflight programme is in danger of withering away. 